\title{
Carbamazepine induces bioactivation of cyclophosphamide and thiotepa
}

\author{
Corine Ekhart $\cdot$ Sjoerd Rodenhuis $\cdot$ \\ Jos H. Beijnen • Alwin D. R. Huitema
}

Received: 7 February 2008 / Accepted: 7 April 2008 / Published online: 24 April 2008

(C) The Author(s) 2008

\begin{abstract}
Purpose We report a patient with metastatic breast cancer who received three cycles of high-dose chemotherapy with cyclophosphamide $\left[1,000 \mathrm{mg} /\left(\mathrm{m}^{2}\right.\right.$ day $\left.)\right]$, thiotepa $(80 \mathrm{mg} /$ $\left(\mathrm{m}^{2}\right.$ day) and carboplatin (dose calculated based on modified Calvert formula with $3.25 \mathrm{mg} \mathrm{min} / \mathrm{ml}$ as daily target AUC) over 4 days, followed by peripheral blood progenitor cell support. During the first two cycles the patient concomitantly used carbamazepine for the treatment of epilepsy. Due to severe nausea and vomiting the patient was unable to ingest carbamazepine; therefore, this was discontinued after the second cycle.

Methods Blood samples were drawn on 2 days (day 1 and 2,3 or 4) of each cycle and plasma levels of cyclophosphamide, its active metabolite 4-hydroxycyclophosphamide, thiotepa, its main, active metabolite tepa and carboplatin were determined.

Results Exposure to 4-hydroxycyclophosphamide and tepa on day 1 was increased in the presence of carbamazepine (58 and $75 \%$, respectively), while exposure to cyclophosphamide and thiotepa was reduced (40 and 43\%, respectively).
\end{abstract}

C. Ekhart $(\varangle) \cdot$ J. H. Beijnen · A. D. R. Huitema

Department of Pharmacy and Pharmacology,

The Netherlands Cancer Institute/Slotervaart Hospital,

Louwesweg 6, 1066 EC Amsterdam, The Netherlands

e-mail: Corine.Ekhart@slz.nl

\section{S. Rodenhuis}

Department of Medical Oncology,

The Netherlands Cancer Institute/Antoni van Leeuwenhoek

Hospital, Amsterdam, The Netherlands

\section{J. H. Beijnen}

Faculty of Pharmaceutical Sciences,

Department of Biomedical Analysis, Section of Drug Toxicology,

Utrecht University, Utrecht, The Netherlands
Conclusion Since increased exposure to the active metabolites is associated with an increased risk of toxicity, it is important to be aware of this drug-drug interaction.

Keywords Pharmacokinetics - Cyclophosphamide . Thiotepa $\cdot$ Carbamazepine

\section{Introduction}

High-dose chemotherapy with autologous peripheral blood progenitor cell support is used in the treatment of several haematological malignancies and solid tumours. Although haematological toxicity is manageable, significant endorgan toxicity may occur [1]. Interpatient variability in drug exposure has been shown to correlate with both toxicity and effectiveness of high-dose chemotherapy [2]. Since pharmacokinetics may correlate with outcome, drug-drug interactions between the cytotoxic agents and concomitant medication may be of clinical importance.

Cyclophosphamide is an inactive prodrug and is activated by cytochrome P450 to 4-hydroxycyclophosphamide. CYP2B6, 2C9, 2C19, 3A4 and 3A5 have been reported to be involved in the 4-hydroxylation, of which CYP2B6 is the most important. Furthermore, cyclophosphamide shows strong autoinduction, resulting in increased clearance of the parent compound and increased formation of its metabolites [3, 4]. Thiotepa is metabolised by CYP2B6 and CYP3A4 to its main metabolite tepa [5]. Thiotepa and tepa have comparable alkylating activity [6].

Here we report the induction of cyclophosphamide and thiotepa metabolism due to carbamazepine, resulting in increased formation of the active metabolites, 4-hydroxycyclophosphamide and tepa, respectively. 


\section{Patient and method}

Case

A 52-year-old female patient was diagnosed with metastatic breast cancer. As part of her treatment she received three cycles of high-dose chemotherapy with autologous peripheral blood progenitor cell transplantation. This regimen consisted of 4 days of chemotherapy with cyclophosphamide $\left[1,000 \mathrm{mg} /\left(\mathrm{m}^{2}\right.\right.$ day $\left.)\right]$ as $1 \mathrm{~h}$ infusion, immediately followed by carboplatin (dose calculated based on modified Calvert formula with $3.25 \mathrm{mg} \mathrm{min} / \mathrm{ml}$ as daily target AUC) as $1 \mathrm{~h}$ infusion and thiotepa $\left[80 \mathrm{mg} /\left(\mathrm{m}^{2}\right.\right.$ day $\left.)\right]$ divided over two $30 \mathrm{~min}$ infusions $12 \mathrm{~h}$ apart. Mesna $(500 \mathrm{mg})$ was administered six times daily for a total of 36 doses, beginning $1 \mathrm{~h}$ prior to the first cyclophosphamide infusion. The three cycles were given with 4 week intervals. The patient prophylactically received antibiotics (ciprofloxacin and fluconazole orally), starting 4 days before chemotherapy. Furthermore, during the chemotherapy cycles the patient received dexamethasone and granisetron. Full details of the tCTC regimen have been published previously [1].

During the first and second cycles the patient received carbamazepine (twice daily $200 \mathrm{mg}$ slow release) and vigabatrin (twice daily $500 \mathrm{mg}$ ) orally for the treatment of epilepsy. Due to severe nausea and vomiting, the patient was unable to ingest carbamazepine. Therefore, after the second tCTC cycle anti-epileptic treatment was stopped and not restarted until after the third tCTC cycle.

Pharmacokinetic analysis

For pharmacokinetic analyses, blood samples were collected from a double lumen intravenous catheter inserted in a subclavian vein. Samples were collected on day 1 and 2, 3 or 4 prior to the start of the infusions at $30 \mathrm{~min}$ after the start of cyclophosphamide infusion $(t=30)$ and $t=60$ (end of cyclophosphamide infusion), 90, 120 (end of carboplatin infusion), 150 (end of thiotepa infusion), 180, 210, 285, $390,660 \mathrm{~min}$ and when possible at $24 \mathrm{~h}$. Thiotepa, tepa and cyclophosphamide were quantified with a validated gas chromatographic assay as described previously. The lower limits of quantitation for thiotepa, tepa and cyclophosphamide were 5,5 and $50 \mathrm{ng} / \mathrm{mL}$, respectively [7]. 4-Hydroxycyclophosphamide was determined as a semicarbazone derivative with a previously described and validated highperformance liquid chromatography assay. The lower limit of quantitation was $50 \mathrm{ng} / \mathrm{mL}$ [8].

A previously published population pharmacokinetic model of thiotepa (and its metabolite tepa) and cyclophosphamide (and its metabolite 4-hydroxycyclophosphamide) was used for estimating the AUC of all compounds using Bayesian analysis [9]. The Committee on the Medical
Ethics of the Netherlands Cancer Institute had approved the protocol and written informed consent was obtained from the patient.

\section{Results}

Plasma concentration versus time curves of cyclophosphamide and 4-hydroxycyclophosphamide of all three cycles are shown in Fig. 1 in combination with the model fitted curves. As can be seen in Fig. 1A, cyclophosphamide clearance on day 1 was increased in the presence of carbamazepine, resulting in a lower cyclophosphamide AUC with a concomitant increase in 4-hydroxycyclophosphamide AUC (Table 1). Furthermore, in the absence of carbamazepine, a more pronounced autoinduction of cyclophosphamide was observed. Cyclophosphamide clearance increased during the 4 days of cycle 3 (Fig. 1a) and the $C_{\max }$ of 4-hydroxycyclophosphamide was increased on day 4 compared to day 1 ( 1.9 vs. $0.99 \mu \mathrm{g} / \mathrm{mL}$ ) of cycle 3 (Fig. 1b). In the presence of carbamazepine, no autoinduction could be identified.

Figure 2 shows the plasma concentration versus time curves of thiotepa and tepa. Thiotepa clearance was increased in the presence of carbamazepine (Fig. 2a), resulting in a lower plasma exposure of thiotepa, with a concomitant increase in tepa AUC (Table 1).

Tables 1 and 2 show the effects of carbamazepine on the AUCs of cyclophosphamide, 4-hydroxycyclophosphamide, thiotepa and tepa on day 1 and during the whole course, respectively. From these tables it can be seen that the effects of carbamazepine on cyclophosphamide and thiotepa pharmacokinetics are more pronounced during the first day of the course.

The pharmacokinetics of carboplatin were similar during the three cycles. Besides severe nausea and vomiting during cycles 2 and 3, no other toxicity was observed during the three cycles.

\section{Discussion}

Here we report an increase in cyclophosphamide and thiotepa metabolism caused by co-administration of carbamazepine. Furthermore, in the presence of carbamazepine, autoinduction of cyclophosphamide is not detectable.

Carbamazepine acts as an anti-convulsant for partial and grand mal seizures. The activity of a variety of cyctochrome P450 enzymes, including CYP1A2, CYP2B, CYP2C9, CYP2C19 and CYP3A4 is induced by carbamazepine [10-12].

Co-administration with carbamazepine is known to decrease values of mean peak plasma concentration and area under the plasma concentration-time curve of many 

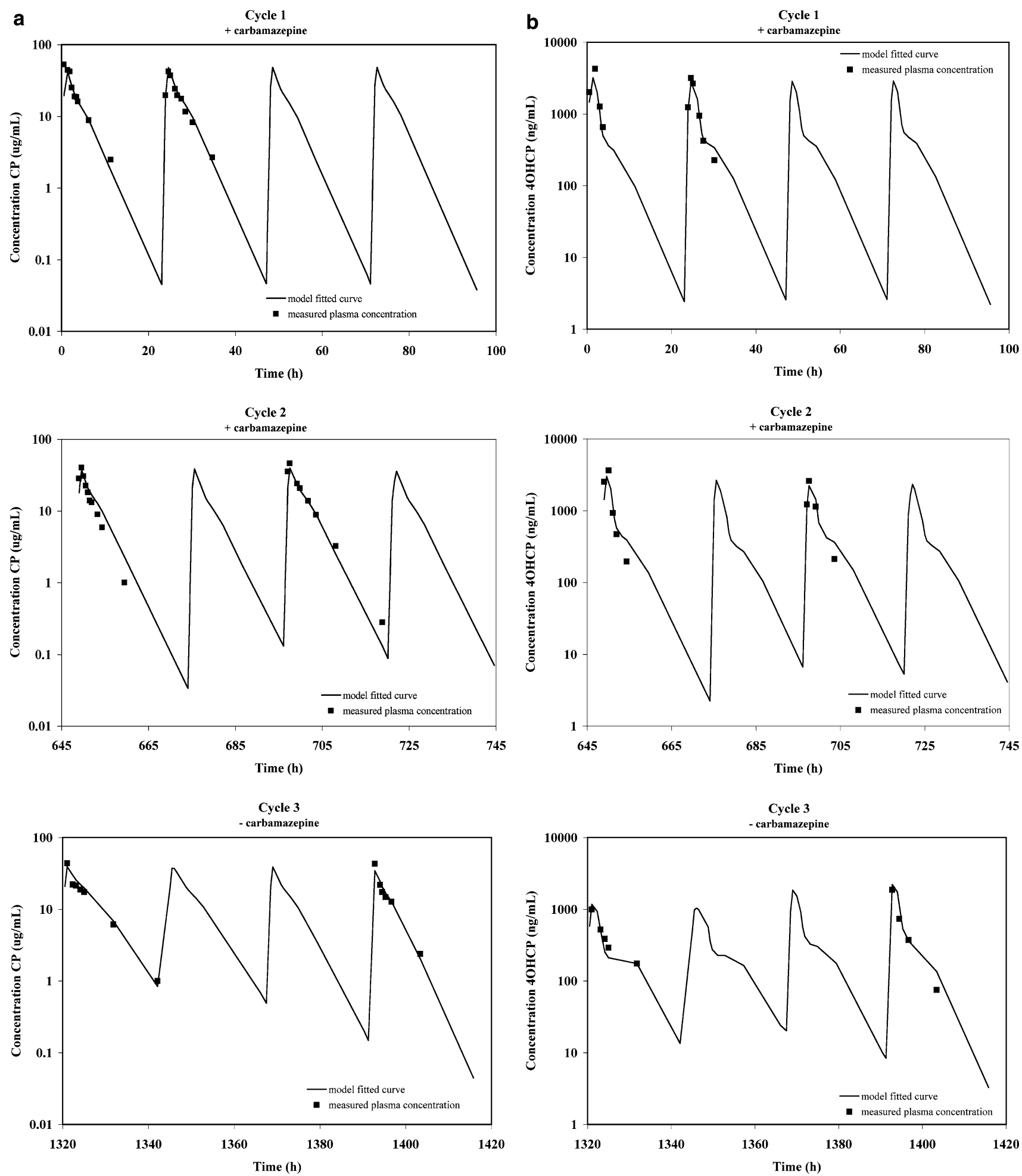

Fig. 1 Plasma concentration versus time curves of a cyclophosphamide (CP 1,780 mg) and b 4-hydroxycyclophosphamide (4OHCP) in three high-dose tCTC chemotherapy cycles, the first and second cycles with carbamazepine and the third cycle without carbamazepine

drugs, resulting in a need to increase the dose of these agents. Carbamazepine and other anticonvulsant drugs have also shown to increase the systemic clearance of chemotherapy, resulting in lower efficacy [13].
The increase in cyclophosphamide and thiotepa clearance observed, may be caused by the induction of CYP enzymes 2B6 and 3A4 which are mainly involved in cyclophosphamide and thiotepa metabolism. The absence of 
Table 1 Effect of carbamazepine on the AUC of day 1 of cyclophosphamide, thiotepa and metabolites

\begin{tabular}{lllr}
\hline Compounds & $\begin{array}{l}\text { Cycles 1 and 2 with } \\
\text { carbamazepine mean AUC } \\
\text { day 1 (AUC cycle 1-AUC } \\
\text { cycle 2) }\end{array}$ & $\begin{array}{l}\text { Cycle 3 without } \\
\text { carbamazepine } \\
\text { AUC day 1 }\end{array}$ & $\begin{array}{l}\text { Difference } \\
(\%)\end{array}$ \\
\hline Cyclophosphamide & $0.57(0.59-0.56) \mathrm{mM} \mathrm{h}$ & $0.95 \mathrm{mM} \mathrm{h}$ & -40 \\
4-Hydroxycyclophosphamide & $31.2(31.8-30.5) \mu \mathrm{M} \mathrm{h}$ & $19.7 \mu \mathrm{M} \mathrm{h}$ & 58 \\
Thiotepa & $11.8(12.3-11.4) \mu \mathrm{Mh}$ & $20.6 \mu \mathrm{M} \mathrm{h}$ & -43 \\
Tepa & $50.3(50.7-50.0) \mu \mathrm{M} \mathrm{h}$ & $28.8 \mu \mathrm{M} \mathrm{h}$ & 75 \\
\hline
\end{tabular}
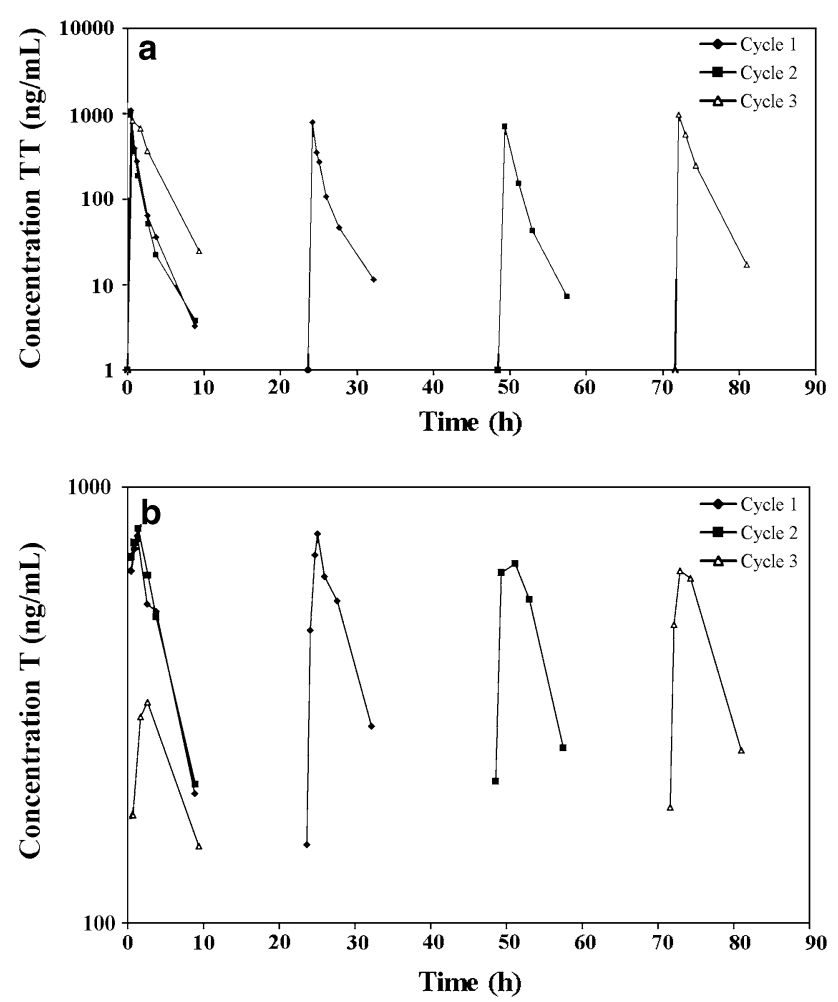

Fig. 2 Plasma concentration versus time curves of a thiotepa (TT $70 \mathrm{mg}$ ) and $\mathbf{b}$ tepa (T), in three high-dose tCTC chemotherapy cycles; filled diamond, the first cycle (with carbamazepine); filled square, the second cycle (with carbamazepine); and open triangle, the third cycle (without carbamazepine)

autoinduction of cyclophosphamide in the presence of carbamazepine is probably due to the metabolising enzymes already being induced by carbamazepine.
The effect of carbamazepine was more pronounced during the first day of the course. The overall AUC of the several compounds was only moderately affected by carbamazepine. This could be due to cyclophosphamide also being an inducer of CYP2B6 and CYP3A4, thereby increasing its own metabolism and the metabolism of thiotepa, if carbamazepine is absent, and therefore producing the same effect as carbamazepine [9].

For both cyclophosphamide and thiotepa, studies have demonstrated that alterations in liver CYP enzyme composition and activity have a major impact on the pharmacokinetics of these agents [14-17]. Xie et al. [18] found one patient with a very high 4-hydroxylation activity in their study into the pharmacogenetics of cyclophosphamide in patients with haematological malignancies. Different from the other patients, this patient was treated with carbamazepine. No other reports have been published, to our knowledge, on the induction of cyclophosphamide and thiotepa metabolism by carbamazepine.

The patient in our report also received vigabatrin. It is unlikely that vigabatrin caused this interaction since vigabatrin does not induce the hepatic cytochrome P450 enzyme system [19].

This report shows that carbamazepine induces the metabolism of cyclophosphamide and thiotepa. This interaction will predominantly be important in single-dose administrations. Increases in exposure to the active metabolites could lead to increased toxicity.

Since the effect of changes in enzyme activity can vary substantially between patients and because of the unpredictability of the magnitude of this effect, it is recommended that carbamazepine is used with precaution with cyclophosphamide and thiotepa.
Table 2 Effect of carbamazepine on the overall AUC of cyclophosphamide, thiotepa and metabolites

\begin{tabular}{lllr}
\hline Compounds & $\begin{array}{l}\text { Cycles 1 and 2 with } \\
\text { carbamazepine mean AUC } \\
\text { (AUC cycle 1-AUC cycle 2) }\end{array}$ & $\begin{array}{l}\text { Cycle 3 without } \\
\text { carbamazepine AUC }\end{array}$ & $\begin{array}{l}\text { Difference } \\
(\%)\end{array}$ \\
\hline Cyclophosphamide & $2.5(2.7-2.3) \mathrm{mM} \mathrm{h}$ & $3.1 \mathrm{mM} \mathrm{h}$ & -19 \\
4-Hydroxycyclophosphamide & $122(123-120) \mu \mathrm{M} \mathrm{h}$ & $95 \mu \mathrm{M} \mathrm{h}$ & 28 \\
Thiotepa & $46.4(48.0-44.8) \mu \mathrm{Mh}$ & $94.0 \mu \mathrm{M} \mathrm{h}$ & -51 \\
Tepa & $233(228-239) \mu \mathrm{M} \mathrm{h}$ & $191 \mu \mathrm{M} \mathrm{h}$ & 22 \\
\hline
\end{tabular}


In a previous report a significant induction of cyclophosphamide and thiotepa metabolism by phenytoin was described [20]. When seizure control is necessary in patients receiving concomitant chemotherapy, drugs that do not influence the hepatic cytochrome P450 enzyme system (gabapentin and levetiracetam) are to be preferred [21].

Acknowledgment This work was supported with a grant from the Dutch Cancer Society (project NKI 2005-3418).

Open Access This article is distributed under the terms of the Creative Commons Attribution Noncommercial License which permits any noncommercial use, distribution, and reproduction in any medium, provided the original author(s) and source are credited.

\section{References}

1. Rodenhuis S, Westermann A, Holtkamp MJ, Nooijen WJ, Baars JW, van der WE et al (1996) Feasibility of multiple courses of high-dose cyclophosphamide, thiotepa, and carboplatin for breast cancer or germ cell cancer. J Clin Oncol 14(5):1473-1483

2. de Jonge ME, Huitema ADR, Rodenhuis S, Beijnen JH (2005) Clinical pharmacokinetics of cyclophosphamide. Clin Pharmacokinet 44(11):1135-1164

3. Roy P, Yu LJ, Crespi CL, Waxman DJ (1999) Development of a substrate-activity based approach to identify the major human liver P-450 catalysts of cyclophosphamide and ifosfamide activation based on cDNA-expressed activities and liver microsomal P-450 profiles. Drug Metab Dispos 27(6):655-666

4. Chang TK, Yu L, Maurel P, Waxman DJ (1997) Enhanced cyclophosphamide and ifosfamide activation in primary human hepatocyte cultures: response to cytochrome P-450 inducers and autoinduction by oxazaphosphorines. Cancer Res 57(10):19461954

5. Jacobson PA, Green K, Birnbaum A, Remmel RP (2002) Cytochrome $\mathrm{P} 450$ isozymes $3 \mathrm{~A} 4$ and $2 \mathrm{~B} 6$ are involved in the in vitro human metabolism of thiotepa to TEPA. Cancer Chemother Pharmacol 49(6):461-467

6. Huitema ADR, Smits KD, Mathot RA, Schellens JH, Rodenhuis S, Beijnen JH (2000) The clinical pharmacology of alkylating agents in high-dose chemotherapy. Anticancer Drugs 11(7):515-533

7. Huitema ADR, Tibben MM, Kerbusch T, Zwikker JW, Rodenhuis S, Beijnen JH (1998) Simultaneous determination of $N, N^{\prime}, N^{\prime \prime}$-triethylenethiophosphoramide, cyclophosphamide and some of their metabolites in plasma using capillary gas chromatography. J Chromatogr B Biomed Sci Appl 716(1-2):177-186
8. Huitema ADR, Tibben MM, Kerbusch T, Kettenes-van den Bosch JJ, Rodenhuis S, Beijnen JH (2000) High performance liquid chromatographic determination of the stabilized cyclophosphamide metabolite 4-hydroxycyclophosphamide in plasma and red blood cells. J Liq Chromatogr Rel Technol 23:1725-1744

9. de Jonge ME, Huitema ADR, Rodenhuis S, Beijnen JH (2004) Integrated population pharmacokinetic model of both cyclophosphamide and thiotepa suggesting a mutual drug-drug interaction. J Pharmacokinet Pharmacodyn 31(2):135-156

10. Tateishi T, Asoh M, Nakura H, Watanabe M, Tanaka M, Kumai T et al (1999) Carbamazepine induces multiple cytochrome P450 subfamilies in rats. Chem Biol Interact 117(3):257-268

11. Glue P, Banfield CR, Perhach JL, Mather GG, Racha JK, Levy RH (1997) Pharmacokinetic interactions with felbamate. In vitro-in vivo correlation. Clin Pharmacokinet 33(3):214-224

12. Perucca $E$ (2006) Clinically relevant drug interactions with antiepileptic drugs. Br J Clin Pharmacol 61(3):246-255

13. Relling MV, Pui CH, Sandlund JT, Rivera GK, Hancock ML, Boyett JM et al (2000) Adverse effect of anticonvulsants on efficacy of chemotherapy for acute lymphoblastic leukaemia. Lancet 356(9226):285-290

14. Yu LJ, Drewes P, Gustafsson K, Brain EG, Hecht JE, Waxman DJ (1999) In vivo modulation of alternative pathways of P-450-catalyzed cyclophosphamide metabolism: impact on pharmacokinetics and antitumor activity. J Pharmacol Exp Ther 288(3):928-937

15. Chang TK, Chen G, Waxman DJ (1995) Modulation of thiotepa antitumor activity in vivo by alteration of liver cytochrome P450-catalyzed drug metabolism. J Pharmacol Exp Ther 274(1):270-275

16. Ng SF, Waxman DJ (1990) Biotransformation of $N, N^{\prime}, N^{\prime \prime}$-triethylenethiophosphoramide: oxidative desulfuration to yield $\mathrm{N}, \mathrm{N}^{\prime}$, $\mathrm{N}^{\prime \prime}$-triethylenephosphoramide associated with suicide inactivation of a phenobarbital-inducible hepatic P-450 monooxygenase. Cancer Res 50(3):464-471

17. Ng SF, Waxman DJ (1991) $N, N^{\prime}, N^{\prime \prime}$-triethylenethiophosphoramide (thio-TEPA) oxygenation by constitutive hepatic P450 enzymes and modulation of drug metabolism and clearance in vivo by P450-inducing agents. Cancer Res 51(9):2340-2345

18. Xie H, Griskevicius L, Stahle L, Hassan Z, Yasar U, Rane A et al (2006) Pharmacogenetics of cyclophosphamide in patients with hematological malignancies. Eur J Pharm Sci 27(1):54-61

19. Besag FM, Berry D (2006) Interactions between antiepileptic and antipsychotic drugs. Drug Saf 29(2):95-118

20. de Jonge ME, Huitema ADR, van Dam SM, Beijnen JH, Rodenhuis S (2005) Significant induction of cyclophosphamide and thiotepa metabolism by phenytoin. Cancer Chemother Pharmacol 55(5):507-510

21. Vecht CJ, Wagner GL, Wilms EB (2003) Treating seizures in patients with brain tumors: Drug interactions between antiepileptic and chemotherapeutic agents. Semin Oncol 30(6 Suppl 19):49-52 